\title{
What influences the use of greenways as active transportation corridors?
}

\author{
Abdulrahman A. Zawawi ${ }^{12^{*}}$ and Nicole Porter ${ }^{2}$ \\ 1 King Abdulaziz University, Saudi Arabia; aazawawi@kau.edu.sa \\ 2 University of Nottingham; nicole.porter@nottingham.ac.uk; \\ * Correspondence: aazawawi@kau.edu.sa
}

Citation: Zawawi, A. A..; Porter, N., 2022, What influences the use of greenways as active transportation corridors? SUPTM 2022 conference proceedings sciforum-053113. https://doi.org/10.31428/10317/10365

Publisher's Note: UPCT and Sciforum stays neutral with regard to jurisdictional claims in published maps and institutional affiliations.

Copyright: (C) 2022 by the authors. Submitted for possible open access publication under the terms and conditions of the Creative Commons Attribution (CC BY) license (https://creativecommons.org/license s/by/4.0/).

\begin{abstract}
Cities worldwide are investing in active transportation (AT) infrastructure, particularly in the form of greenways (GWs), to advance several sustainable transport and quality of living agendas. However, many of those investments have not increased the rate of AT and the use of those GWs for utilitarian purposes. To understand why this is the case, a systematic literature review was conducted to identify the factors that influence the use of GWs as AT corridors. Results show that commuters' perceptions, behaviours, and needs of GWs differ from other user types of GWs. An understanding of these factors should inform the planning, design, and management of GWs to maximise their AT potential.
\end{abstract}

Keywords: Greenways; Active Transportation; Systematic Literature Review; Sustainable Transport.

\section{Introduction}

According to the European Greenways Association, greenways are "Communication routes reserved exclusively for non-motorised journeys, developed in an integrated manner which enhances both the environment and quality of life of the surrounding area" [1]. Active transportation (AT) is a form of physical activity, and both are motivators for using greenways (GWs) [2]. Cities worldwide are investing in AT infrastructure, particularly in the form of GWs, to advance several sustainable transport and quality of living agendas $[2,3]$. However, many of those investments have not increased the rate of AT and the use of those GWs for utilitarian purposes, as reported by several case studies [4-13]. This study explored why this is the case and sought to identify the factors that influence the use of greenways as AT corridors.

\section{Methodology}

A two-phased systematic literature review was conducted about the use and users of greenways (from 1991 until 2021). Table 1. identifies the search engines and terms used to look for the relevant journal articles in both phases, following a similar approach to a recent systematic literature review of greenway use [14]. The first phase used the term "greenway" to find relevant articles, with database searches returning 1176 articles. To ensure additional relevant articles not present in searched databases were identified, snowballing of cited literature from screened articles and recent systematic literature reviews [14-16] was conducted, adding an additional 31 articles (phase one). Most of these additional articles not identified via database searches did not use the term "greenway" and instead used the word "trail" as a synonym. Therefore, the second phase of database search used the term "trail use" to capture other relevant articles (a total of 519 and Science Direct was the only search engine used in this phase due to time constraints). A total of 1726 articles were identified from both search phases. 
Table 1. Database search strategy.

\begin{tabular}{|c|c|c|}
\hline Electronic database & Search terms (all conducted in June of 2021) & Results \\
\hline Web of Science & Used the term "greenway" (via Publons). & 123 \\
\hline \multirow[t]{2}{*}{ Science Direct } & $\begin{array}{l}\text { Phase one: used the term "greenway." AND typed "greenway" in the Title, abstract or author- } \\
\text { specified keywords field (from advanced search). }\end{array}$ & 229 \\
\hline & $\begin{array}{l}\text { Phase two: used the term "trail users" and limited the search from the following journals: } \\
\text { - Journal of Outdoor Recreation and Tourism (118) } \\
\text { - Urban Forestry \& Urban Greening (140) } \\
\text { - Landscape and Urban Planning (261) }\end{array}$ & 519 \\
\hline Scopus & $\begin{array}{l}\text { Used the term "greenway" in the search field, then limited the search results to articles with } \\
\text { keywords that included "greenway" AND "Greenways." Boolean term (TITLE-ABS-KEY ( } \\
\text { greenway ) AND ( LIMIT-TO ( EXACTKEYWORD, "Greenways") OR LIMIT-TO ( } \\
\text { EXACTKEYWORD, "Greenway") ) }\end{array}$ & 213 \\
\hline $\begin{array}{l}\text { From University of } \\
\text { Nottingham online li- } \\
\text { brary search }\end{array}$ & $\begin{array}{l}\text { Searched for Anywhere with the exact phrase "greenway" AND Title with the exact phrase } \\
\text { "transport." }\end{array}$ & 284 \\
\hline $\begin{array}{l}\text { Fabos Conference on } \\
\text { Landscape and Green- } \\
\text { way Planning }\end{array}$ & Scanned all 327 articles from 2010 until 2019. & 327 \\
\hline \multicolumn{2}{|c|}{$\begin{array}{l}\text { Number of articles from both snowballing of screened articles in phase one and examination of previous systematic } \\
\text { reviews about greenways. }\end{array}$} & 31 \\
\hline & Total & 1726 \\
\hline
\end{tabular}

All 1726 articles were processed through two levels of screening criteria to identify the ones with AT use as one of the main parts of its inquiry. The first level mainly focused on the use and users of greenways, which resulted in 90 articles. Each of those screened articles was categorised based on GW type, country, and city. Then, the second round of screening was applied to select only articles that focused on active commuters via GWs, resulting in 20 out of 90 articles. Those articles were reviewed in detail to identify the factors that influence the use of GW as AT corridors.

Identifying those factors had two layers of analysis: the forms of GW use and the factors affecting their use. GW use indicators were divided into two parts: reported from users (e.g., use purpose, frequency, and duration via a questionnaire) and calculated using measurement tools (e.g., pedestrian and cyclists' volumes using automated counters). Factors were divided into socio-economic and demographic influences; weather and temporal influences; environmental and accessibility influences; influences of GW characteristics; and finally, travel behaviour and individual influences. Under each of those categories, multiple variables were identified from a detailed analysis.

Furthermore, identified variables in each of the 20 articles were analysed to precisely describe which were influential to using GWs as AT corridors. Therefore, results differentiated dependent variables (types or qualities of use) from independent ones (factors affecting their use) and their relationship.

\section{Results}

Based on the detailed analysis of the 20 articles, research findings identified patterns in their aims, study types, and research methods. For example, most studies were quantitative, using regression and chi-square analyses, and none were entirely qualitative. Thus, several scholars emphasised the need for more qualitative studies to understand better how trail siting and design influence trail use and the perception of trail users [5, 13]. In addition, results also identified shared characteristics of a commuter via GWs, the effects of commuting via GWs on its users and nearby residents, and the factors that influence the use of GWs as AT corridors. Figure 1 summarises those factors based on the 20 articles. 


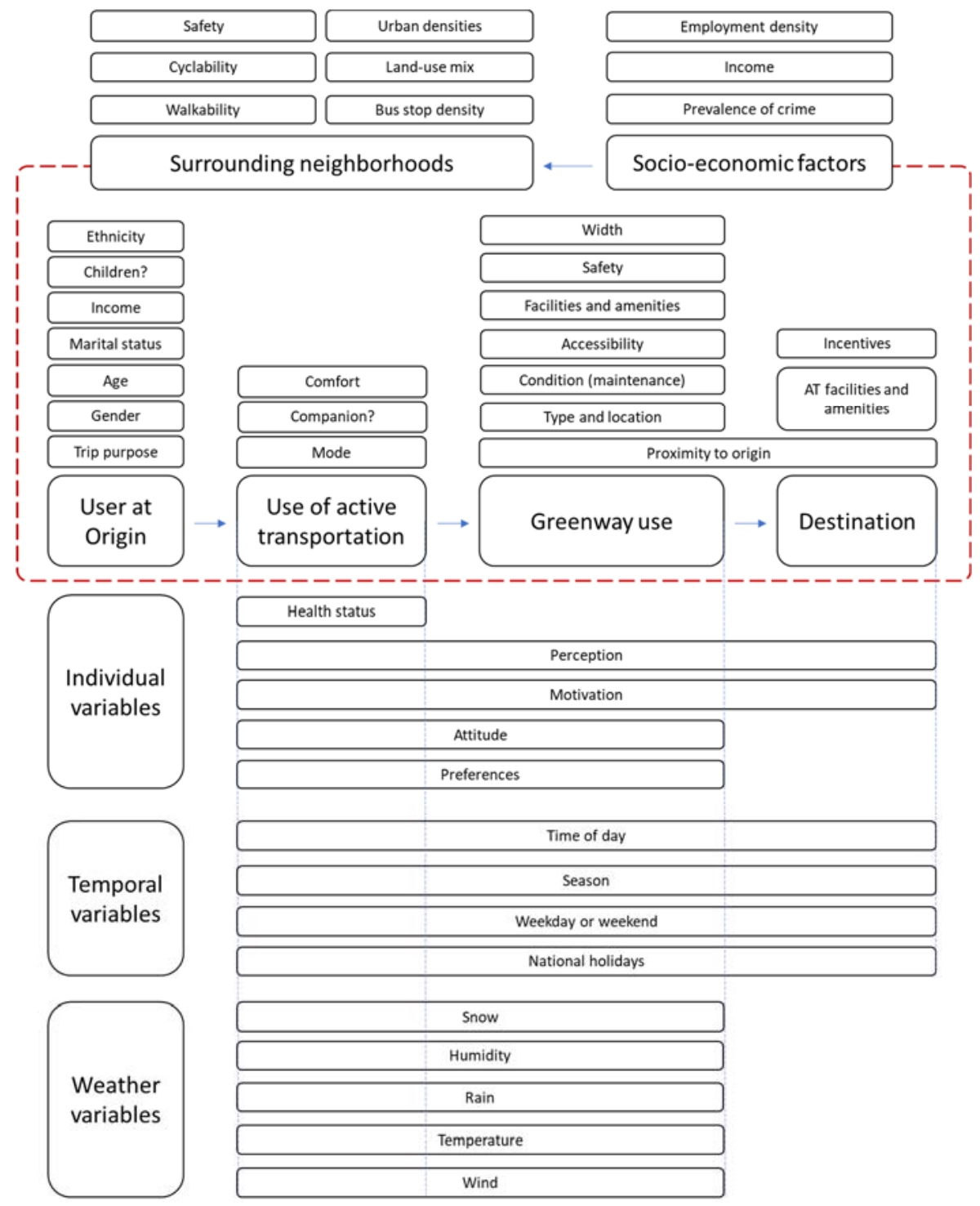

Figure 1. Factors that influence the use of greenways as active transportation corridors.

Additionally, results showed that commuters' perceptions, behaviours, and needs of GWs differ from other types of GW users. For instance, GW's distance from home strongly influences the propensity of its use as an AT corridor and increases the likelihood of active commuting. Furthermore, AT via GWs usually occurs during weekdays, and those commuters are often more tolerant of weather impacts than weekend users whose trips are mostly recreational at an hourly level $[4,9,17]$. These two observations are examples of several identified patterns that distinguish commuters via GWs from other user types.

However, results varied according to differences in GW types and locations, study objectives, time of year, and analytical methods, making it difficult to identify generalisable patterns. Nonetheless, careful, contextualised consideration of those factors can inform the planning and design of GWs to maximise their use, unlock their use potential, enhance their users' experience, and develop their management and operational strategies.

\section{Conclusion}

Identifying literature that is focused on the use of GWs as AT corridors can be problematic for several reasons. First, more than two-thirds of the identified "greenway use" literature is US-based, a biased result that could be attributed to the term's origin. Second, the term "greenway" will never capture all relevant literature since its international adoption is limited. Moreover, many scholars use specific rather than generic terms to describe 
their project type (e.g., rail-trail or waterfront). Therefore, the use of the term "greenway" 1 should always be followed by a physical description of its characteristics to (1) minimise confusion, especially for newcomers to this field, and (2) channelise its knowledge development streams while facilitating access to the "greenway use" literature. Third, the GW concept evolved to include transport-led GWs (e.g., Comox-Helmcken GW in Vancouver, Canada) that may lack vegetation in some or all of its segments. Such contemporary expressions that associate "green" with a broader sustainability and liveability agenda can further divide opinions on what qualifies as a GW, a concern voiced but justified by others $[14,18]$. Therefore, the potential disagreement among scholars may prevent a clear exchange of ideas and evidence-based research. Fourth, based on search engines such as Science Direct and Scopus, there is a considerable gap in knowledge about GW use internationally. Thus, contributions to this body of knowledge, especially case studies from the Middle East and Africa, are needed.

Funding: This research received no external funding.

Acknowledgements: Not applicable.

Conflicts of Interest: The authors declare no conflict of interest.

\section{References}

1. EGWA. Greenways I Asociación Europea de Vías Verdes http://www.aevv-egwa.org/greenways/\# (accessed Jan 20, 2019).

2. Lindsey, G.; Qi, Y.; Gobster, P. H.; Sachdeva, S. The 606 at Three: Trends in Use of Chicago's Elevated Rail-Trail. In Proceedings of the Fábos Conference on Landscape and Greenway Planning; 2019; Vol. 6, p 37. https://doi.org/10.7275/18qq-n116.

3. Lindsey, G. Sustainability and Urban Greenways: Indicators in Indianapolis. J. Am. Plan. Assoc. 2003, 69 (2), 165-180. https://doi.org/10.1080/01944360308976304.

4. Chen, N.; Lindsey, G.; Wang, C. H. Patterns and Correlates of Urban Trail Use: Evidence from the Cincinnati Metropolitan Area. Transp. Res. Part D Transp. Environ. 2019, 67, 303-315. https://doi.org/10.1016/j.trd.2018.12.007.

5. Evenson, K. R.; Herring, A. H.; Huston, S. L. Evaluating Change in Physical Activity with the Building of a Multi-Use Trail. In American Journal of Preventive Medicine; 2005; Vol. 28, pp 177-185. https://doi.org/10.1016/j.amepre.2004.10.020.

6. Gobster, P. H. Perception and Use of a Metropolitan Greenway System for Recreation. Landsc. Urban Plan. 1995, 33 (1-3), 401413. https://doi.org/10.1016/0169-2046(94)02031-A.

7. Lindsey, G. Use of Urban Greenways: Insights from Indianapolis. Landsc. Urban Plan. 1999, 45 (2-3), 145-157. https://doi.org/10.1016/S0169-2046(99)00023-7.

8. Lindsey, G.; Nguyen, D. B. L. Use of Greenway Trails in Indiana. J. Urban Plan. Dev. 2004, 130 (4), $213-217$. https://doi.org/10.1061/(asce)0733-9488(2004)130:4(213).

9. Mundet, L.; Coenders, G. Greenways: A Sustainable Leisure Experience Concept for Both Communities and Tourists. J. Sustain. Tour. 2010, 18 (5), 657-674. https://doi.org/10.1080/09669581003668524.

10. Troped, P. J.; Saunders, R. P.; Pate, R. R. Comparisons between Rail-Trail Users and Nonusers and Men and Women's Patterns of Use in a Suburban Community. J. Phys. Act. Heal. 2005, 2 (2), 169-180. https://doi.org/10.1123/jpah.2.2.169.

11. Troped, P. J.; Whitcomb, H. A.; Hutto, B.; Reed, J. A.; Hooker, S. P. Reliability of a Brief Intercept Survey for Trail Use Behaviors. J. Phys. Act. Heal. 2009, 6 (6), 775-780. https://doi.org/10.1123/jpah.6.6.775.

12. Wolch, J. R.; Tatalovich, Z.; Spruijt-Metz, D.; Byrne, J.; Jerrett, M.; Chou, C. P.; Weaver, S.; Wang, L.; Fulton, W.; Reynolds, K. Proximity and Perceived Safety as Determinants of Urban Trail Use: Findings from a Three-City Study. Environ. Plan. A 2010, 42 (1), 57-79. https://doi.org/10.1068/a41302.

13. Wolff-Hughes, D. L.; Fitzhugh, E. C.; Bassett, D. R.; Cherry, C. R. Greenway Siting and Design: Relationships with Physical Activity Behaviors and User Characteristics. J. Phys. Act. Heal. 2014, 11 (6), 1105-1110. https://doi.org/10.1123/jpah.2012-0444.

14. Paneerchelvam, P. T.; Maruthaveeran, S.; Maulan, S.; Shureen, S. F. The Use and Associated Constraints of Urban Greenway from a Socioecological Perspective: A Systematic Review. Urban For. Urban Green. 2020 , 47. https://doi.org/10.1016/j.ufug.2019.126508.

15. Horte, O. S.; Eisenman, T. S. Urban Greenways: A Systematic Review and Typology. Land. MDPI AG February 1, 2020. https://doi.org/10.3390/land9020040.

16. Senes, G.; Rovelli, R.; Bertoni, D.; Arata, L.; Fumagalli, N.; Toccolini, A. Factors Influencing Greenways Use: Definition of a Method for Estimation in the Italian Context. J. Transp. Geogr. 2017, 65 (November), $175-187$. https://doi.org/10.1016/j.jtrangeo.2017.10.014.

17. Zhao, J.; Guo, C.; Zhang, R.; Guo, D.; Palmer, M. Impacts of Weather on Cycling and Walking on Twin Trails in Seattle. Transp. Res. Part D Transp. Environ. 2019, 77, 573-588. https://doi.org/10.1016/j.trd.2019.09.022.

18. Turner, T. Greenway Planning in Britain: Recent Work and Future Plans. Landsc. Urban Plan. 2006,76 (1-4), $240-251$. https://doi.org/10.1016/j.landurbplan.2004.09.035.

18

19 20 21 22 23 24 25 26 